\title{
The Development of Decision-Making Maps for the High-Speed Machining (HSM) of Rhyodacite (Carijó Basalt) in Milling-Based Processing Applications
}

\author{
Hélio Dorneles Etchepare, Wilson Kindlein Júnior \\ PPG3M, Federal University of Rio Grande do Sul, Porto Alegre, Brazil \\ Email: helioeco@gmail.com
}

Received September 17, 2013; revised October 28, 2013; accepted November 11, 2013

Copyright (c) 2013 Hélio Dorneles Etchepare, Wilson Kindlein Júnior. This is an open access article distributed under the Creative Commons Attribution License, which permits unrestricted use, distribution, and reproduction in any medium, provided the original work is properly cited.

\begin{abstract}
The demand for innovative products that overcome competitive pricing and conquer market shares can be met by interdisciplinary approaches that bridge product design, engineering and technology. Ornamental and covering stones stand out among the materials in need of innovation and are commonly used in architecture and construction as coverings in urban elements, funerary art, and art and decor. In spite of the many applications of ornamental stones, products with low added value are typically observed. Although Brazil displays significant geological potential for ornamental stones, its actual market participation is as a supplier of un- or semi-processed stones. Even with the market's visible expansion and Brazil's increased representation in the market, the technological advances used in the final processing of stones are restricted to improve the tools used for cutting, especially the durability of diamond-coated tools, and for polishing, which, in the short-term, meets the demands for marketing, producing and distributing semi-finished products. Accordingly, a little exploited aspect of ornamental stones appears, especially for “carijó basalt” (rhyodacite), that is, the inclusion of new processing and value-adding technologies or the inclusion of non-conventional processes in the sector. The goals of this work are to study and develop HSM (high speed machining) CNC (computer numerically controlled) milling processes that are applicable to rhyodacite, specifically to determine the milling parameters that give the best results for machining time with respect to tool wear and material abrasion and to replicate the results obtained in the samples. The results show that the raw material used in the present study, because it is natural, presents significant variations in composition and hardness, which prevent specific milling parameters from being determined. However, using a post-processor specifically developed for this study, it was possible to draft a decision-making map that aids in the execution of this process. Additionally, equipment failure occurred during every attempt and with every adjustment of the milling process. This indicates that the application of multipoint tools to rhyodacite milling is difficult in this industry. Thus, the use of single-point tools should be the natural path to follow for a potential practical industrial application in Brazil.
\end{abstract}

Keywords: Technology; Rocks; Processing; Multidisciplinarity

\section{Introduction}

According to Brazil's Ministry for Mines and Energy (MME) [1], in a report from 2001, the country's covering rock sector can be divided into 18 productive groups composed of entrepreneurial activities in 7 states and 80 municipalities. The main product in the state of Rio Grande do Sul is basalt. The report states that Brazil has 11.500 companies in this sector, providing 120.000 direct jobs and possessing facilities capable of processing from 40 to $50 \mathrm{~m}^{3}$ /year, which represents a production of 6.0 million tons/year. Basalt stands out, with approximately 7\% of this total. According to Bizzi (2003), the commercial transactions in the sector, including machinery, equipment and raw materials, corresponded to approximately US\$ 2.5 billion in 2003 [2].

Carijó basalt has been used as a covering material in construction and is extracted mainly from a region in the northeast of the Rio Grande do Sul state, known as the "Basalt Region," due to the significant number of extraction and processing companies present there. This "Ba- 
salt Region” encompasses, according to the Basalt Magazine (Syndicate of the Quarry Exploitation Industry of Nova Prata and Region, 2000) [3], the municipalities of André da Rocha, Guabijú, Nova Araçá, Nova Bassano, Nova Prata, Paraí, Protásio Alves, São Jorge, Veranópolis, Vila Flores and Vista Alegre do Prata (Figure 1).

According to data made available by the Chamber of Industry and Commerce (Câmara de Indústria e Comércio-CIC) on the Basalt Region, the gross revenue generated from extracting and processing this material is 501.3 million Brazilian Reais, of which approximately 52.7 million Brazilian Reais are paid as taxes and 37 million Brazilian Reais are paid as salaries. Additionally, the an export volume is approximately 48 million Brazilian Reais, all of which make this industry one of the most important industries in the region due to its significant participation in the state- and country-level economies [4].

There are 300 mining areas in the region, according to data published in the journal Socio-Economical Hierarchy of the Basalt Region. In the municipality of Nova Prata alone, also known as the National Basalt Capital, there are 104 registered mining and 89 basalt processing companies, which represent $10 \%$ of the municipality's economy and provide approximately 3000 jobs, both direct and indirect. Table 1 shows the main products of basalt processing in Nova Prata, as well as their volumes and corresponding fractions [4].

Given the latent potential of using computer numerically controlled techniques in rock processing applications, in the present article, we seek to systematically study the viability of using HSM milling in this context and to determine the best machining parameters for this purpose.

\section{HSM Milling}

According to Dieter (1981) [5], in general, two distinct

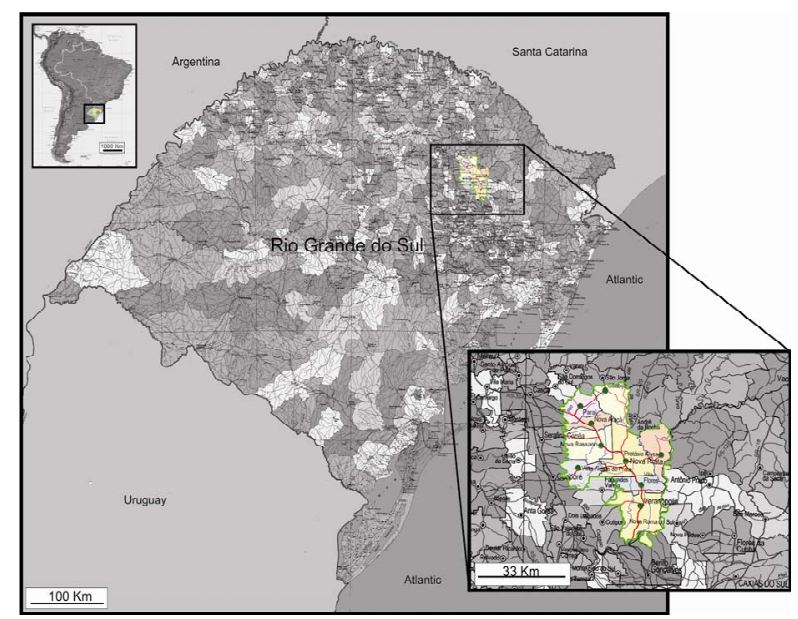

Figure 1. The Basalt Region in Rio Grande do Sul. manufacturing classes are utilized in the solid state, including deformation processes, in which the desired shape is produced through plastic deformation of the materials while preserving their initial volume, and machining processes, in which part of the material is removed through specific processes to produce the target shape. Machining processes are used to produce parts with high dimensional tolerance, good surface finishes and relatively complex shapes. Currently, significant technological developments have been achieved in machining processes, particularly with the addition of computer numerically controlled (CNC) and high speed machining (HSM) techniques, which guarantee precision and repeatability of movement. One of the machining areas that has benefited most significantly from these developments is, according to Faller et al. (2006), the field of milling processes [6].

In HSM milling, the machine (Figure 2) interprets

Table 1. The products obtained from basalt.

\begin{tabular}{ccc}
\hline Main products & Volume produced $\left(\mathrm{m}^{3} /\right.$ year $)$ & (\%) \\
\hline Paving stone & 30,000 & 50 \\
Slabs & 6000 & 10 \\
Irregular pieces of stone paving & 12,000 & 20 \\
Foundation stones & 6000 & 10 \\
Other & 6000 & 10 \\
Total & 60,000 & 100 \\
\hline
\end{tabular}

Adapted in 08/01/2011 from the Chamber of Industry and Commerce, Basalt Region, 2010.

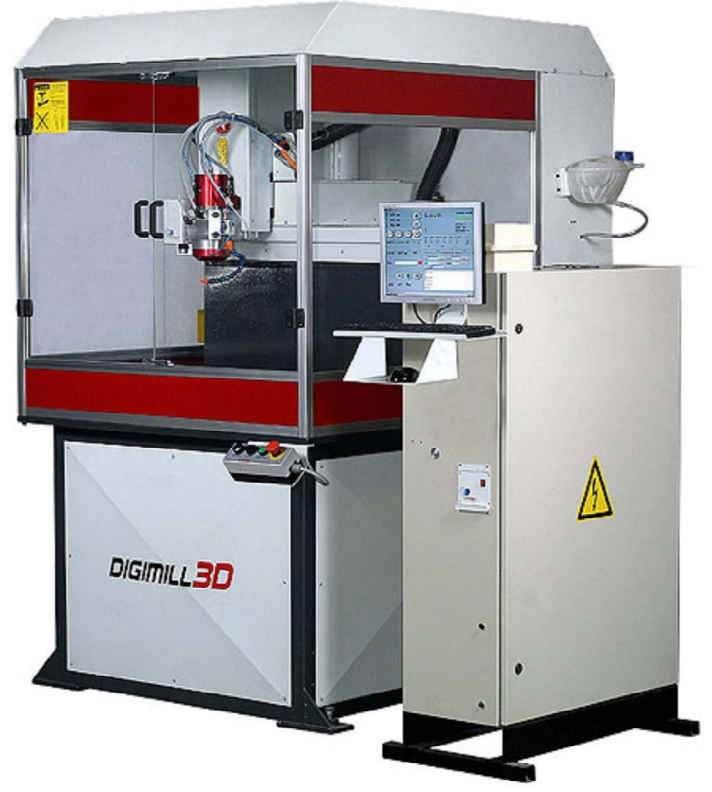

Figure 2. The CNC Digimill 3D milling centre. Adapted in 11/28/2012 from http://www.tecnodrill.com/prod_03.htm. 
digital instructions and activates a set of servos and stepper motors that control each axis of the machine $(\mathrm{X}, \mathrm{Y}$ and $\mathrm{Z}$ in the case of 3 -axis milling machines), moving the table or the tool in an automatic and interpolated manner (movement can be made simultaneously along all axes). Some or all of the numerical data are converted during the process, e.g., distances, angles, speeds, etc., which allows almost any shape to be conceived/manufactured in real applications. The arrival of this technology was only possible after the necessary tools, automation and informatics were invented.

Any machining process depends critically on the material from which the tool is made and the interaction of the machining forces with the workpiece, where the mechanical properties of the tool, especially its hardness, should be superior to those of the raw material (the workpiece to be machined).

The development of machining tools has generally been accompanied by technological developments, both with respect to the specific characteristics of the raw materials and the specialisation of manufacturing processes. Machining tools generate surfaces in two ways: by using a profile tool, the shape of which resembles the shape of the surface to be produced, or by advancing the tool along the part's length. Profile tools are relatively more expensive but are important in line production applications. Machining parameters, such as the cutting depth, the $\mathrm{X}$-, Y- and Z-speeds, and the spindle ${ }^{1}$ rotation speed, all of which vary according to the material and tool, as noted by Freitas (2006) [7], should be considered to prevent excessive tool and/or equipment wear. Most cutting tools are made of cast steel or hard metal, according to Dieter (1981), but there are also tools made of fused alloys and others possessing diamond coatings, with the latter being more suited in the processing of ornamental stones.

Figueira (2006) [8] points out that diamond-coated tools are the most commonly employed tools in the blasting, cutting and polishing processes for ornamental rocks, ceramics and non-ferrous materials. According to Stemmer (2008) [9], the extraordinary hardness of diamond, which exceeds that of any other material, can vary between 5000 and 7000 on the Knoop scale, or 56 to 102 GPa (giga-Pascal), depending on the crystal's orientation. The high thermal conductivity of diamond can hinder the performance of polycrystalline tools because of the premature tearing of the abrasive grains due to the absorption by the metallic matrix of the heat generated from the friction between the workpiece and the tool. The potential usefulness of numerical control in stone processing has prompted the discussion of applying HSM milling to cutting applications for this type of material to verify the best conditions for its application.

\footnotetext{
${ }^{1}$ device that provides the tool with rotation.
}

\section{Materials and Methods}

According to the Brazilian Geological Service, CPRM [10], the stones used in this study, extracted from mining areas in the Basalt Region, are part of the Geological Province of Paraná flood basalts, the Caxias Facies, which formed in the Cretaceous period between 65 and 135 million years ago. This facies consists mainly of massive basalt flood of intermediate to acidic composition, mafic and with fine granular texture and lamellar structures, which explains why extraction is performed in the horizontal orientation.

According to Motoki (2004) [11], the plateau that is stratigraphically called the Serra Geral mountain range, spanning across the states of Santa Catarina and Rio Grande do Sul, is composed mainly of basalt lava with high iron and low silica contents. However, at the top of these mountains, the basaltic lava is covered by rhyodacite, a volcanic rock with low iron and high silica contents, which is often mistaken for and commercialised as basalt [12].

Three plates of this material were acquired to better assess its characteristics and to obtain an overall better understanding of its nature: one measuring $95 \times 60 \times 2$ $\mathrm{cm}^{3}$, labelled "control," and two smaller plates, labelled "random," one measuring $74 \times 11 \times 2 \mathrm{~cm}^{3}$ and the other measuring $45 \times 15 \times 2 \mathrm{~cm}^{3}$. The plates were obtained from different quarries in the Basalt Region. The control plate, which was visually darker than the other plates, was mapped and subdivided into 425 specimens measuring $3 \times 3 \times 2 \mathrm{~cm}^{3}$. The random plates, both exhibiting a red tone, were subdivided into 93 samples of $3 \times 3 \times 2$ $\mathrm{cm} 3$ without control of specimen position. The test bodies were washed to remove surface dust and were then dehumidified for 24 hours (Figure 3).

A set of 22 samples was selected to characterise the rock with respect to hardness using Knoop's test and chemical composition using X-ray diffraction analysis. Of these samples, 11 were taken from the control plate and 11 from the random plates, specifically, samples B2, B9, B17, B24, I5, I13, I21, P2, P9, P17 and P24 from the control plate and samples $1,9,17,25,33,49,57,65,73$, 81 and 89 from the random plates. For the X-ray fluorescence assay, a subset of 11 samples was taken from the aforementioned set, namely, samples I7, B2, B17, I5, I13, I21, P9, P17, and P24 (control) and 1 and 9 (random).

The results from the hardness tests, X-ray diffraction and fluorescence analyses and petrography indicated that it was not necessary to classify the samples prior to the machining tests given their homogeneity. For the rhyodacite tests, the machining parameters used for steel were taken as the initial reference values because of the significant hardness and well-known parameters of this material. However, because diamond-coated (polycrystal- 

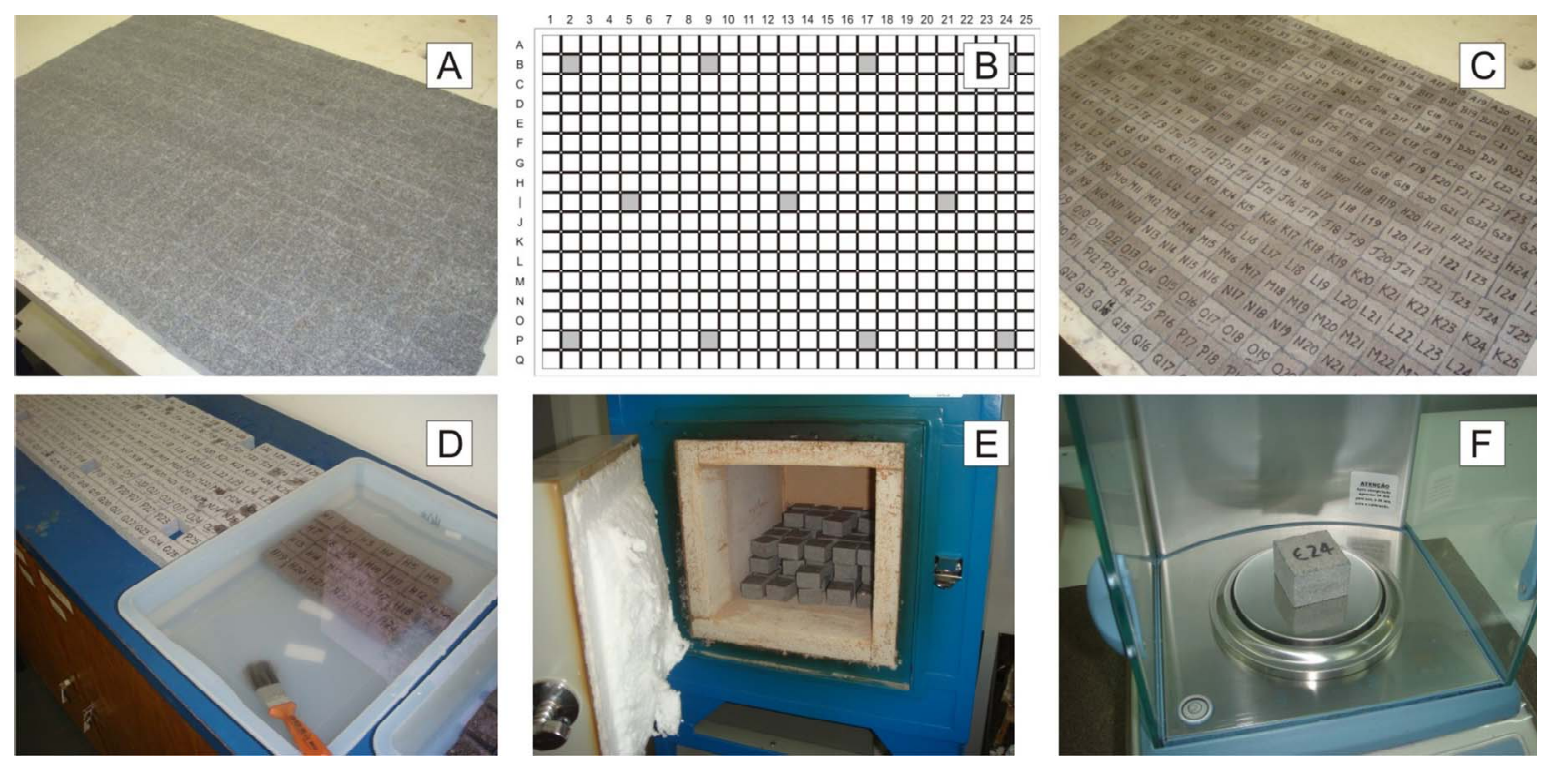

Figure 3. The control plate (A) was mapped (B) and subdivided into 425 specimens of $3 \times 3 \times 2 \mathrm{~cm}^{3}$ (C). The samples indicated on the map (B) were analysed for hardness using Knoop's test, $\mathrm{X}$-ray diffraction and fluorescence and petrography. All samples were washed (D) and dehumidified by evaporation for $24 \mathrm{~h}(\mathrm{E})$, and their masses were assessed using a digital analytical scale (F).

line with nickel matrix) tools were intended for use, the spindle rotation was altered to 23,000 rpm.

Additionally, to minimise possible variations, 100 tools of the KG Sorensen ${ }^{\circledR}$ brand model 3018 batches 2266 and 5359 were purchased. The tools were classified according to their diameter, measured with a Mitutoyo ${ }^{\circledR}$ digital calliper accurate to the $0.001 \mathrm{~mm}$. The diameters of the tools varied between 2.766 and $3.005 \mathrm{~mm}$, with an average diameter of $2.911 \mathrm{~mm}$ and a standard deviation of $0.04 \mathrm{~mm}$. By statistically considering $95 \%$ of these measurements to be accurate, tools with diameters smaller than $2.81 \mathrm{~mm}$ were discarded. The mass of each tool was measured using a precision scale and was found to vary between $0.3193 \mathrm{~g}$ and $0.3372 \mathrm{~g}$, with an average weight of $0.3219 \mathrm{~g}$. Measurements of the mass and length of each tool were used to determine their wear relative to the established machining parameters.

\section{Rhyodacite Milling Tests}

To initiate testing, all rhyodacite samples were calibrated according to their planeness, and a fixing support, levelled with the help of a dial gauge, was adapted to the milling centre to allow the samples to be quickly exchanged. Additionally, two ISO 15488-A collet chucks were purchased; these chucks were capable of holding tools with shanks between 1 and $2 \mathrm{~mm}$ in diameter. The goal of such procedures was to optimise the setup times. All proposed patterns were milled according to the parameters given in Figure 4.

All tests were performed using water-soluble mist coolant (Unix Solúvel 100 for light machining) diluted at the ratio of $1 / 19$, as recommended by the manufacturer. For all patterns except number 4 , the tests were performed with one tool each, and no loss of mass was detected; for pattern 4, however, it was necessary to use 4 tools in separate tests, for which the speed was gradually reduced to $6.38 \mathrm{~mm} / \mathrm{sec}, 25 \%$ below the standard speed used in the steel tests and other rhyodacite tests. None of these procedures was successfully concluded. Because of the lack of success for pattern 4, due to the excessive wear of the lower end of the tools being used, which was caused by the significant number of plunges into the sample, an alternative strategy was tested, namely, raster machining, originally from the $\mathrm{X}$-axis to the $\mathrm{Y}$-axis. This change in the machining direction reduced the number of vertical, i.e., Z-axis, displacements of the tool from 486 to 126 , thus significantly decreasing the impact on the sample. Maintaining the same parameters as that used for steel, the machining time based on this new strategy, as estimated by the $\operatorname{ArtCAM}^{\circledR}$ software, would be $57 \mathrm{~min}$ and $53 \mathrm{sec}$, which corresponds to a reduction of $9 \mathrm{~min}$ and $58 \mathrm{sec}$ in the total machining time.

New assays were performed, at first excluding the displacement variables in $\mathrm{X}$ and $\mathrm{Y}$, to determine the speed along the Z-axis, which wears the tool the least. It was possible to conclude through these tests that the Z-axis speed should be decreased and possibly that the speeds along the $\mathrm{X}$ - and $\mathrm{Y}$-axes should be increased to optimise the processing time and minimise tool wear. This conclusion led to a new proposal for speed control, namely, independent control along the X-, Y- and Z-axes, which was not possible in the $\operatorname{ArtCAM}^{\circledR}$ and $\operatorname{EdgeCAM}^{\circledR}$ CAM 


\begin{tabular}{|c|c|c|}
\hline Description & Plaster Manufacturing & "Carijó Basalt" Manufacturing \\
\hline $\begin{array}{l}\text { Pattern } 1 \text { - flat and smooth geom } \\
\text { - stratcgy - raster } \\
\text { - final depth }-3 \mathrm{~mm} \\
\text { - horizontal step }-0.2 \mathrm{~mm} \\
\text { - vertical step }-0.5 \mathrm{~mm} \\
\text { - feed speed }-12 \mathrm{~mm} / \mathrm{seg} \text {. } \\
\text { - plundge speed }-4 \mathrm{~mm} / \mathrm{seg} \text {. } \\
\text { - rotation speed }-23000 \mathrm{RPM} \\
\text { - machining time }-49 \mathrm{~min} 37 \mathrm{seg} \text {. } \\
\text { - material removed - } 2700 \mathrm{~mm}^{3}\end{array}$ & & $10 \mathrm{~mm}$ \\
\hline $\begin{array}{l}\text { Pattern 2 - tilted profile } \\
\text { - strategy - raster } \\
\text { - final depth }-3 \mathrm{~mm} \\
\text { - horizontal step }-0.2 \mathrm{~mm} \\
\text { - vertical step }-0.5 \mathrm{~mm} \\
\text { - feed speed }-8.5 \mathrm{~mm} / \mathrm{seg} \text {. } \\
\text { - plundge speed }-4 \mathrm{~mm} / \mathrm{seg} . \\
\text { - rotation speed }-23000 \mathrm{RPM} \\
\text { - machining time }-55 \mathrm{~min} 17 \mathrm{seg} . \\
\text { - material removed - } 1350 \mathrm{~mm}^{3}\end{array}$ & $\mathrm{~mm}$ & $0 \mathrm{~mm}$ \\
\hline $\begin{array}{l}\text { Pattern } 3 \text { - concave profile } \\
\text { - slralegy - rasler } \\
\text { - final depth }-3 \mathrm{~mm} \\
\text { - horizontal step }-0.2 \mathrm{~mm} \\
\text { - vertical step }-0.5 \mathrm{~mm} \\
\text { - teed speed }-8.5 \mathrm{~mm} / \mathrm{seg} \text {. } \\
\text { - plundge speed- } 4 \mathrm{~mm} / \mathrm{seg} . \\
\text { - rotation speed - } 23000 \mathrm{RPM} \\
\text { - machining time }-55 \mathrm{~min} 08 \mathrm{seg} \text {. } \\
\text { - material removed }-885,67 \mathrm{~mm}^{3}\end{array}$ & & $\mathrm{~mm}$ \\
\hline $\begin{array}{l}\text { Pattern } 4 \text { - square profile with well } \\
\text { defined vertical walls and corners } \\
\text { - straleyy - rasler } \\
\text { - final depth - } 3 \mathrm{~mm} \\
\text { - horizontal step - } 0.2 \mathrm{~mm} \\
\text { - vertical step }-0.5 \mathrm{~mm} \\
\text { - feed speed }-6.4 \mathrm{~mm} / \mathrm{seg} \text {. } \\
\text { - plundge speed }-1.5 \mathrm{~mm} / \mathrm{seg} \text {. } \\
\text { - rotation speed }-23000 \mathrm{RPM} \\
\text { - machining time }-1 \mathrm{H} 16 \mathrm{~min} 51 \mathrm{seg} \text {. } \\
\text { - material removed - } 1575 \mathrm{~mm}^{3}\end{array}$ & & $\mathrm{~mm}$ \\
\hline $\begin{array}{l}\text { Pattern } 5 \text { - wave profile } \\
\text { - strategy - raster } \\
\text { - final depth - } 3 \mathrm{~mm} \\
\text { - horizontal step - } 0.2 \mathrm{~mm} \\
\text { - vertical step }-0.5 \mathrm{~mm} \\
\text { - feed speed }-8.5 \mathrm{~mm} / \mathrm{seg} . \\
\text { - plundge speed }-4 \mathrm{~mm} / \mathrm{seg} . \\
\text { - rotation speed }-23000 \mathrm{RPM} \\
\text { - machining time }-59 \mathrm{~min} 58 \mathrm{seg} . \\
\text { - material removed }-879.68 \mathrm{~mm}^{3}\end{array}$ & & $\mathrm{~mm}$ \\
\hline $\begin{array}{l}\text { Pattern } 6 \text { - free profile representing } \\
\text { variations of complex geometry } \\
\text { - strategy - raster } \\
\text { - final depth - } 3 \mathrm{~mm} \\
\text { - horizontal step }-0.2 \mathrm{~mm} \\
\text { - vertical step }-0.5 \mathrm{~mm} \\
\text { - feed speed }-8.5 \mathrm{~mm} / \mathrm{seg} \text {. } \\
\text { - plundge speed - } 4 \mathrm{~mm} / \mathrm{seg} \text {. } \\
\text { - rotation speed - } 23000 \mathrm{RPM} \\
\text { - machining time - } 1 \mathrm{H} 38 \mathrm{~min} 34 \mathrm{seg} \text {. } \\
\text { - material removed - } 1444.96 \mathrm{~mm}^{3}\end{array}$ & & $\mathrm{~mm}$ \\
\hline
\end{tabular}

Figure 4. A finishing comparison between geometric patterns based on the dissertation of Gustavo Freitas (2006) [7] machined in plaster and “carijó basalt.”

software packages being used.

Because of the difficulties encountered in finding a software package that permits the independent control of each speed, it was necessary to develop a post-processor to allow control over the basic speed in the experiment. To do this, the post-processor analyses the CNC program generated by the CAM software, in this case a file with. tap extension, and individually sets specific values for the $\mathrm{X}$ - (or Y-, depending on the strategy adopted) and
Z-axis speeds, thus allowing precise control and machining time optimisation. Aside from independent X-, Yand Z-axis speed controls, the post-processor allows the user to change the feed speeds without having to redo the programs in the CAM software based on the analysis of the trigonometric coordinates in $\mathrm{X}$ (or $\mathrm{Y}$ ) and $\mathrm{Z}$ in the program. It also allows free control of these speeds at the user's discretion, as well as of the negative Z-axis displacement, by considering the angle of the surface to be 
machined, which can be constrained to an operator defined range.

A total of 65 tests were performed using the different machining patterns introduced in Figure 4. The parameters used to execute these machining processes for pattern 1 (smooth and flat geometry), 2 (tilted profile), 3 (concave profile), 5 (wave profile) and 6 (free profile) achieved efficiencies between $85 \%$ (pattern 1) and 66\% (pattern 5). The machining process of pattern 4 had a success rate below $10 \%$, making it the hardest pattern to execute.

All tests considered satisfactory had their repeatability verified in a new specimen by using a new tool and the same criteria and standards. Even with rigorous control over the advancing speed in all three movement axes of the tool, when using the post-processor, it was not possible to determine the set of optimal parameters that would allow the procedure to be repeated without constant intervention in the various established parameters.

Among the many variables inherent in any machining process, such as variations in the equipment and tools, greater control exists for those variables that are related to the tools, which are easier to measure and classify according to a pattern. However, the raw material used in this study, rhyodacite, which is a natural material, presents variations that directly interfere with the tool's wear pattern, preventing uniformity and the determination of a specific set of parameters that can be used in general HSM milling processes with this type of equipment, cooling system and tool.

However, because success was obtained under certain conditions, we can trace a decision-making map to assist with this type of job. The map considers, as its initial reference, the pre-established surface patterns used in this study and the actions taken to perform the tests until a positive result was achieved.

The development of the decision-making map is divided into two steps: in the first step (decision making map 1), only the procedures that are possible without using a post-processor are considered; in the second step (decision-making map 2), parameter control is performed in a way that can only be accomplished when using the post-processor. All patterns from Figure 4 were machined without using the post-processor. Its use, however, optimises and makes the procedures easier, faster and less likely to damage the tools.

Initially, in decision-making map 1 , the fundamental parameters are established based on the parameters that yielded successful rhyodacite milling events. For patterns 1, 2, 3, 5 and 6, the feed and plunge speeds (FS and PS, respectively), as well as the horizontal and vertical steps (HS and VS, respectively) are equivalent because the forces to which these tools are subjected are similar. For pattern 4, however, the feed and plunge speeds were re- duced to minimise these forces. A significant fraction of the surface textures used in commercial products can be fitted, as previously discussed, to one of the six patterns or a combination thereof (Figure 5(A)).

Decision-making map 1 starts with the milling of a rhyodacite surface using pre-established parameters. After the initial procedure is completed, the success of the procedure is ascertained. If it has not been successful, the suggestion is to use a different cutting tool and restart the process with the same parameters (Figure 5(B)). Again, the success of the process is ascertained. If it was once more not successful, the tool's wear is determined, which may occur in one of two moments, either during the process, i.e., as the tool is actually machining, or during entry, i.e., as the tool plunges into the surface at the start of the process. The operator is ultimately responsible for observing under which conditions the wear occurred (Figure 5(C)).

In the case of wear during the process, it is suggested that the advance speed be reduced by $10 \%$ (or $50 \%$ for pattern 4). In both cases, this speed reduction is relative to the initial value of the parameter. Afterwards, it is suggested that the tool be exchanged and that the procedure be restarted. If the procedure was not concluded and no visible wear has occurred, then the tool is likely damaged (broken or buckled), and a new speed reduction of $10 \%$ (or $50 \%$ for pattern 4 ) should be applied, along with a $0.1 \mathrm{~mm}$ reduction in the vertical step to minimise axial stresses. The process should then be started with a new tool (Figure 5(D)).

Should the tool continue to wear or break despite all of these recommended actions, the surface to be machined should be zoned, i.e., divided into areas that vary according to the dimensions of the tested samples. For each sector, a new tool must be used, and the process must be restarted. At the end of the procedure in the first area, the success is ascertained (Figure 5(E)).

If success is not attained, the tool must be checked for damage at its tip or buckling. This wear can occur in two situations, either when the tool enters the rhyodacite at the start of the machining process or during the machining process when the tool moves along the $\mathrm{X}$ - or $\mathrm{Y}$ - and $\mathrm{Z}$-axes. Here again, the operator's attention is necessary to determine in which situation the damage has occurred.

If damage occurs during the machining process, it is suggested that the feed speed be reduced by $10 \%$ (or $50 \%$ for pattern 4 ), which minimises the axial stresses and favours processing. Conversely, if wear is observed during entry, the plunge speed must be reduced by $10 \%$, which minimises premature wearing of the tools. In either case, the speed reduction is relative to the initial parameter. After these changes have been implemented, the tool must be exchanged, and the procedure is restarted. If the procedure is not concluded and no visible wear has 


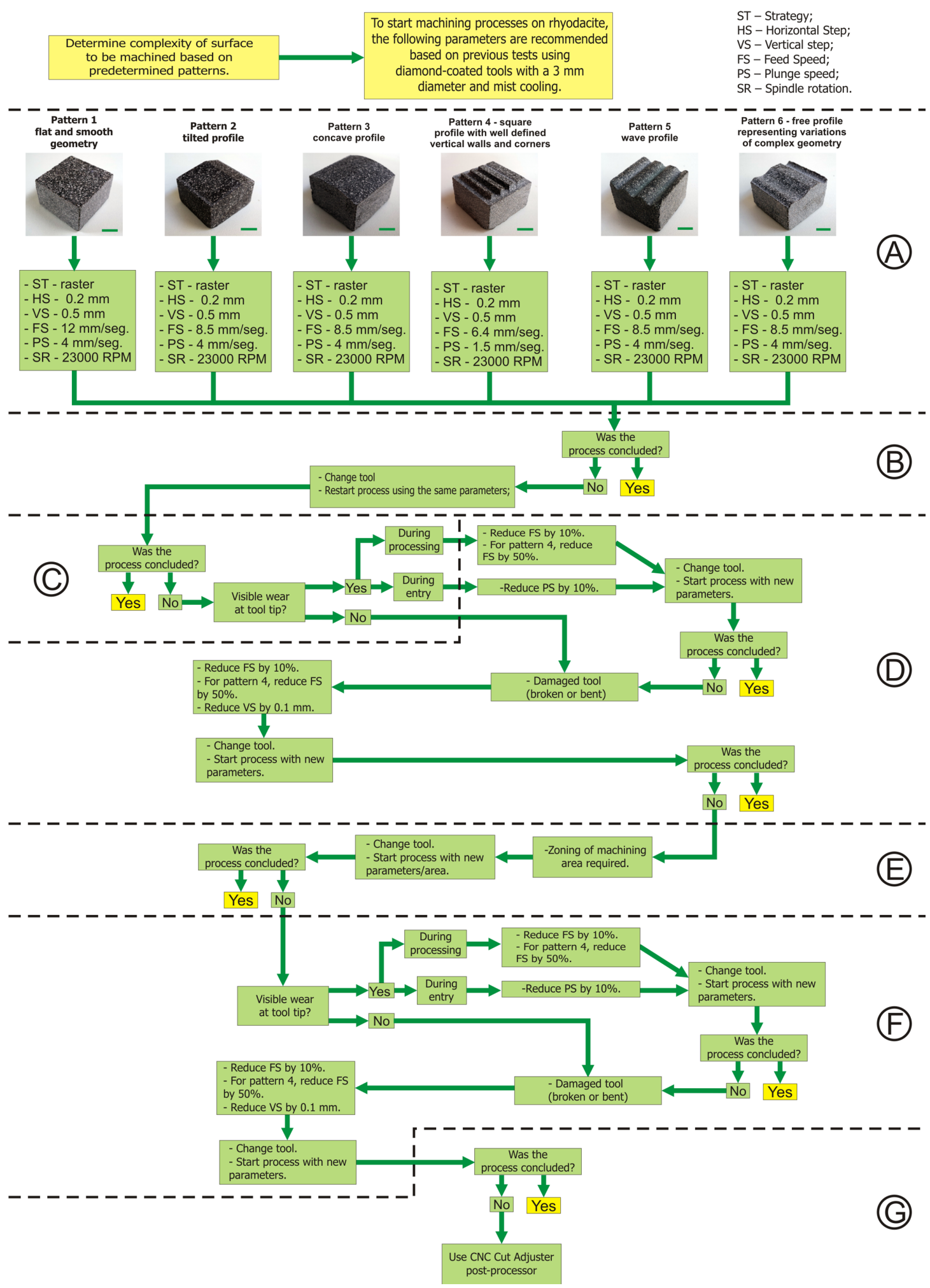

Figure 5. Decision-making map, without the use of the CNC Cut Adjuster software for adjusting the machining parameters for rhyodacite.

occurred, the tool is damaged (bent or broken), and a new reduction in feed speed of $10 \%$ (or $50 \%$ for pattern 4 ) with a $0.1 \mathrm{~mm}$ reduction in the vertical step, relative to the previously used parameters, must be applied to minimise the axial stresses during machining. The process must be restarted at the area being worked with a new 
tool (Figure 5(F)). The success of the procedure is once more ascertained. If even with all of these interventions there is no conclusion and no improvement in the machining conditions and/or reduction with respect to tool damage, then it is not be possible to finalise the procedure (Figure 5(G)).

In decision-making map 2 (Figure 6), the process occurs after all initial parameters have been reset. This

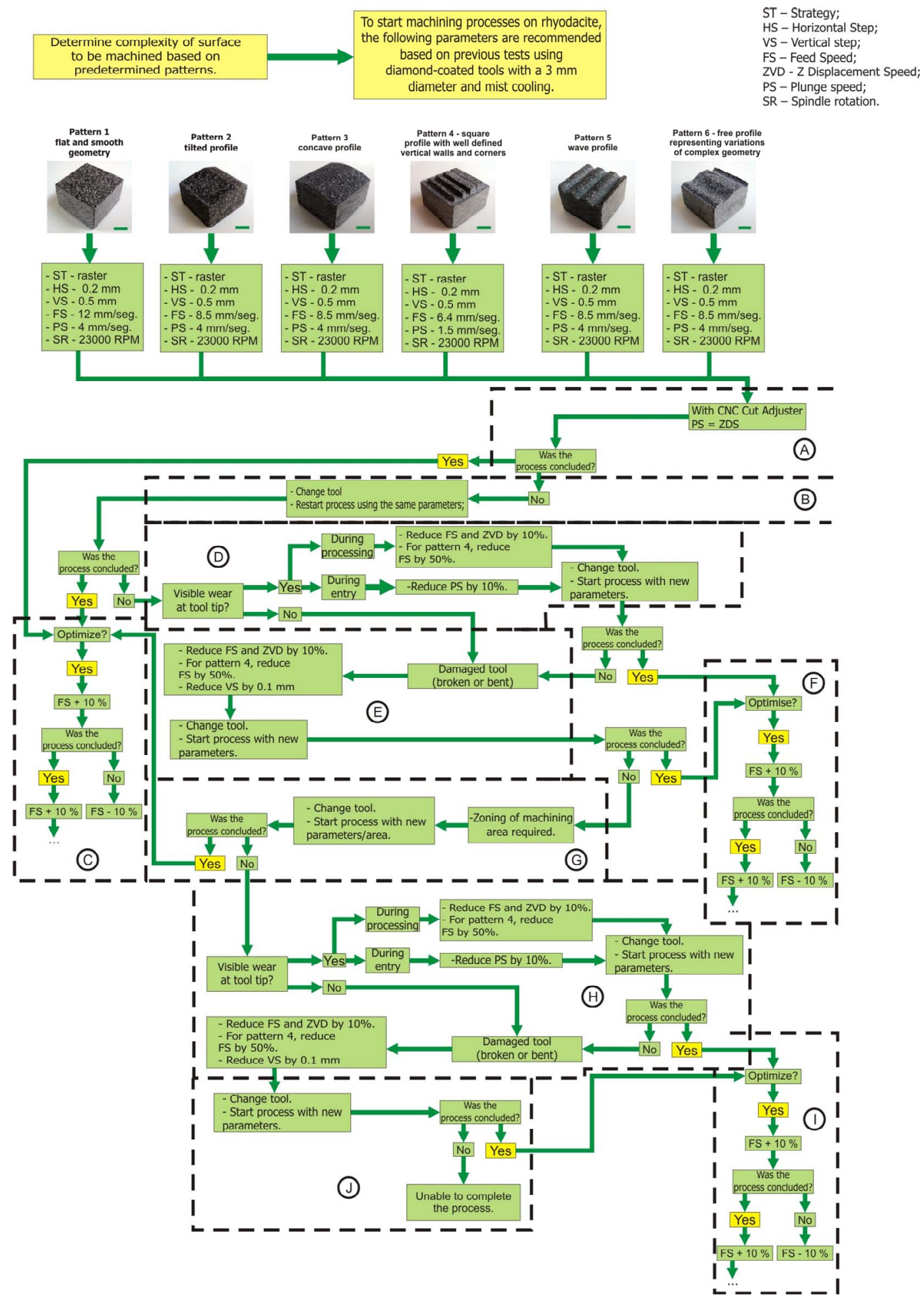

Figure 6. Decision-making map, taking into account the use of the CNC Cut Adjuster software to adjust the machining parameters for rhyodacite. 
procedure is suggested so that the starting point is well known. Using the CNC Cut Adjuster post-processor developed in this work, it is suggested that the vertical displacement speed in $\mathrm{Z}$ (ZS) be made equal to the plunge speed (PS) defined in the CAM software. This way, all descending displacements in $\mathrm{Z}$ are reduced in speed, which favours tool preservation (Figure 6(A)). Changing the advance, $\mathrm{Z}$ displacement and plunge speeds is not possible without this software. After the process is finished, its success is ascertained. In the case of failure, it is suggested that the tool be changed and that the procedure be restarted using the same parameters (Figure 6(B)). The success of the procedure is once more ascertained. In case of success, it may be possible to optimise the procedure by increasing the feed speed by $10 \%$ and repeating the procedure. If success is obtained again, the feed speed may once more be increased by $10 \%$; in the case of failure, the previous increase is retracted (Figure 6(C)). If the process failed to achieve completion, the tool's wear must be determined, which may occur in one of two moments, as shown in decision-making map 1, either during the process, i.e., as the tool is moved by the milling machine, or during entry, i.e., as the tool plunges into the surface at the start of the process. The operator must observe under which conditions the wear has occurred (Figure 6(D)).

For wear during the process, the suggestion is to reduce the feed speed and Z-axis displacement speed by $10 \%$ (or $50 \%$ for pattern 4 ); however, for wear during entry, the suggestion is to reduce the plunge speed by $10 \%$. In both cases, the speed reduction is relative to the initial parameter. Next, it is suggested that the tool be exchanged, and the procedure is restarted. If the procedure fails to conclude and no visible wear occurs, the tool is likely damaged (buckling or breakage), which requires a new reduction of $10 \%$ (or $50 \%$ for pattern 4 ) for the feed and Z-axis displacement speeds with a $0.1 \mathrm{~mm}$ reduction of the vertical step to minimise the axial stresses, after which the process should be restarted with a new tool (Figure 6(E)). Because it is easier to control the machining parameters, it is possible, when the process concludes successfully, to optimise the procedure by gradually improving the X-speed of the tool in $10 \%$ increments. As the feed speed is increased, the chance of damage is also increased. If the tool becomes damaged, then it is necessary to restart the procedure with the most recent feed speed for which success was obtained (Figure 6(F)). After implementing all of these suggestions, if tool wear or damage continues to occur, it becomes necessary to zone, i.e., to divide, the surface to be machined according to the dimensions of the samples tested. For each sector, a new tool must be used, and the process is restarted. At the end of the procedure in the first area, the success of the procedure is ascertained (Figure 6(G)).
In the case of failure, whether the tool incurred any damage, such as wear at the tip or buckling, must be determined. This wear, as previously mentioned, can occur in one of two situations, either during the tool's entry into the rhyodacite, i.e., at the beginning of the machining process, or during the machining process as the tool moves along the $\mathrm{X}$ - or $\mathrm{Y}$ - and Z-axes. The determination of the situation in which damage occurred requires accurate observation by the operator. Should the observed wear occur during the machining process, it is suggested that both the feed and Z-axis displacement speeds be reduced by $10 \%$ (or $50 \%$ for pattern 4 ). This minimises the axial stresses and favours processing. However, if the wear is observed during entry, it is necessary to reduce the plunge speed by $10 \%$, thus minimising premature wear of the tool. In either case, the reduction in speed is relative to the initial parameter. After these changes, it is necessary that the tool be changed, and the procedure is restarted. If the procedure was not completed and no visible wear has occurred, the tool is damaged (bent or broken), and a new reduction of $10 \%$ (or $50 \%$ for pattern 4) in the feed and Z-axis displacement speeds must be made to minimise the axial forces during machining. It is necessary to restart the process in the zone being worked with a new tool (Figure 6(H)). Once again, the success of the process is ascertained. If the machining process concludes, then it is possible to optimise the procedure as previously described (Figure 6(I)). With all of these interventions, if there is no conclusion and no improvement in the machining conditions and/or reduction in tool damage, then it is not be possible to finalise the procedure (Figure 6(J)).

\section{Conclusions}

In this article, we present a characterisation study of the material behaviour of rhyodacite ("carijó" basalt), a stone material, including its processing by high speed machining (HSM). Our approach enhanced our understanding of the necessary processing conditions for rhyodacite and achieved a deeper understanding of this material's characteristics. The technological contributions of this study can be found in the systematisation of the HSM milling procedure and the development of decision-making maps to increase the possibilities of successfully processing this stone material.

The original contributions of this study are related to the use of low-cost diamond-coated polycrystalline tools for rhyodacite processing while correlating the rock properties with tool wear, with the goal of determining the applicable parameters.

The results of this study have shown that the low-cost diamond-coated polycrystalline tools with nickel matrix, obtained from the market, were not able to withstand the forces to which they were subjected. This made it neces- 
sary, here in Brazil, to elaborate a specific post-processor to obtain more control over the parameters provided by CAM software packages. However, it was extremely difficult to maintain the machining parameters, and countless failure problems were encountered with the multipoint tool.

This study suggests that adopting the use of HSM tools for the industrial-scale processing of rhyodacite in Brazil would require technological developments towards lowcost diamond-coated tools, the cost of which should be compatible with the commercial value of this rock; the recommendation is to start with monocrystal diamond tools or single-point tools fabricated with high hardness ceramics, such as tungsten carbide, cubic boron nitride and PCD.

\section{REFERENCES}

[1] Brazil-Ministry for Mines and Energy, "Development of Studies for Drafting the Duodecenial Plan (2010-2030) of Geology, Mining and Mineral Transformation,” 2009.

[2] A. Motoki, "Petrographic Description of Igneous Rocks," State University of Rio de Janeiro, Rio de Janeiro, 2004

[3] L. A. Bizzi, C. Schobbenhaus, R. M. Vidotti and J. H. Gonçalves, "Tectonic Geology and Mineral Resources of Brazil,” CPRM-Brazilian Geological Service, 2003.
[4] Basalt Magazine, "Nova Prata: Syndicate of the Quarry Exploitation Industry of Nova Prata and Region,” 2000.

[5] CIC, "Socio-Economical Hierarchy of the Basalt Region,” Chamber of Industry and Commerce-CIC, Nova Prata, 2010.

[6] G. E. Dieter, "Mechanical Metallurgy," 2nd Edition, Guanabara Dois, Rio de Janeiro, 1981.

[7] R. Faller, F. Silva and W. Kindlein, "The Use of Very High Speed Machining with Four Axes in the Product Design,” VII P\&D Design, Curitiba, 2006.

[8] G. Freitas, "Methodology and Applicability of LASER 3D Digitalisation of Molds for Shoes and Components," UFRGS, Porto Alegre, 2006.

[9] M. Filgueira and D. G. Pinatti, "Development of a New Processing Route for Diamond-Coated Tools: Metallurgy of Powder and Rotary Forging,” Revista Matéria, Vol. 11, No. 3, 2006, pp. 181-188.

[10] C. E. Stemmer, "Cutting Tools II: Drills, Reamers, Taps, Milling Cutters, Broaches, Grinding and Abrasive Wheels," UFSC, Florianópolis, 2008.

[11] CPRM, Company of Research on Mineral Resources/ Brazilian Geological Service, 2010. http://www.cprm.gov.br

[12] A. Motoki, L. Zucco, T. Vargas, J. L. Neves, "Basalt of the Serra Gaúcha Mountain Range and its Relation to Regional Development," 2nd Brazilian Conference of University Extension, Belo Horizonte, 2004. 